\title{
Percepções das Puérperas frente ao Recém-Nascido na UTI Neonatal de um Hospital em Juazeiro do Norte - CE
}

Yaskara Mychaelle Almeida Alencar ${ }^{l}$; Sara

$s^{2}$; Martha Maria Macêdo Bezerra ${ }^{3}$

Resumo: Este é um estudo descritivo com abordagem qualitativa, cujos objetivos foram: identificar os sentimentos e comportamentos das mães em relação a situação que vivenciam; observar a participação da mãe no convívio com o RN internado na UTIN e descrever os conhecimentos das puérperas em relação aos cuidados prestados pela equipe da neonatologia. O cenário foi uma unidade neonatal localizada em Juazeiro do Norte-CE. Os sujeitos foram as puérperas de prematuros. O instrumento de coleta de dados foi a entrevista semiestruturada, realizada nos meses de setembro e outubro de 2014. Na analise dos dados identificou-se as seguintes categorias: Vivenciando uma difícil experiência de ver seu filho internado numa UTIN; Percebendo os sentimentos de puérperas frente ao seu filho internado na UTIN. Concluiu-se que as puérperas demonstram sentir desespero, tristeza,nervosismo e medo da morte ao ver seu filho na UTIN. Porém ao mesmo tempo é reconhecido o valor da UTIN de salvar a vida dos bebês. A pesquisa nos aponta a fragilidade emocional das mães e a intervenção dos profissionais na aproximação do vínculo mãe-bebê.

Palavras-Chave: puérperas, UTIN, sentimentos, prematuros

\section{Perceptions of Recently Given Birth in the face of the Newborn in Neonatal ICU of a Hospital in Juazeiro do Norte-CE}

\begin{abstract}
This is a descriptive study with a qualitative approach, whose objectives are to identify the feelings and attitudes of mothers about the situation they experience, observe the mother's participation in the meeting with the RN from the NICU and describe the knowledge of the mothers for about care provided by the team of neonatology. The scenario was a neonatal unit located in Juazeiro do Norte-CE. The subjects were the mothers of infants. The instrument of data collection was a semi-structured interview, conducted during September and October 2014. In the data analysis identified the following categories: experiencing a difficult experience of seeing his son admitted in a NICU; Realizing the feelings of mothers front of his son from the NICU. It was concluded that the mothers show feel despair, sadness, nervousness and fear of death to see his son in the NICU. But at the same time recognized the value of the NICU to save the lives of babies. The research shows us the emotional fragility of the mothers and the involvement of professionals in bringing the mother-baby.
\end{abstract}

Key- Words: postpartum, NICU, feelings, premature

\section{Introdução}

Para a mulher uma das fases mais importantes da sua vida é o nascimento de um filho, principalmente quando planejado. O período gestacional é uma etapa da constituição da maternidade, na qual estabelece o exercício do papel ativo materno, cujo auge se dá após o nascimento.

\footnotetext{
${ }^{1}$ Graduada em Enfermagem pela Faculdade Dr. Leão Sampaio, em Juazeiro do Norte- CE

${ }^{2}$ Bacharelado em Enfermagem pela Faculdade Leão Sampaio. Especialista em Urgência e Emergência no atendimento pré-hospitalar pela Faculdade leão Sampaio; Especialista em Saúde da Família pela faculdade Integrada de Patos. Cursando especialização em Auditoria no sistema de saúde. E-mail: sara_jua@ @otmail.com;

${ }^{3}$ Mestrado em Educação pela Universidade Estadual do Ceará (2013) Possui Licenciatura em Pedagogia pela Universidade Regional do Cariri (1994), especialização em Língua Portuguesa pela Universidade Estadual do Ceará (1995), especialização em Políticas Públicas pela Universidade Regional do Cariri (2001), especialisação em Saude Mental e Psiquiatria pela Universidade Estadual do Vale do Acaraú (2013). Atualmente, cursa o Doutorado em Saúde Coletiva pela Faculdade de Medicina do ABC. Professora concursada da Secretaria de Educação do Estado do Ceará. Professora da Rede Municipal de Juazeiro do Norte. E-mail: dblf@ig.com.br.
} 
Para Iserhard et al., (2009), "apesar da gestação ser considerada um processo normal da fisiologia feminina, é um momento especial na vida das mulheres, pois cada uma vivencia a gravidez de forma diferente, experimentando de forma singular as repentinas mudanças decorrentes desta fase nos níveis físico, emocional, social e familiar".

Durante a gestação são criados planos, expectativas e ansiedades em torno do nascimento do bebê, principalmente no momento do parto. Porém quando nasce prematuramente é levado para Unidade de Terapia Intensiva Neonatal (UTIN), aonde a mãe sente-se só e vê seu sonho se transformar em desespero e dúvida, fazendo com que a genitora sinta-se insegura e preocupada tanto em relação aos cuidados do recém-nascido (RN) em si como ao seu futuro, ficando impotente diante da situação.

Até mesmo durante a amamentação que é um período onde mãe e filho criam um vínculo maior, a puérpera vê-se em situação mecânica, onde a alimentação do $\mathrm{RN}$ é feita por profissionais e equipamentos, sem o calor materno. Essas e outras situações dificultam a mãe de exercer o seu papel e impedem o RN de receber os cuidados maternos.

A mãe deve ser orientada a visitar o recém-nascido, porém o primeiro encontro acaba sendo uma experiência estressante e assustadora, pois ela nunca esteve em um local como a UTIN. Cabe a equipe de enfermagem facilitar os contatos iniciais à genitora passando as informações para onde o $\mathrm{RN}$ foi levado, quais os cuidados prestados e, sobretudo o direito de vê-lo quando quiser, exercendo a atenção humanizada, adaptando-a ao local, incentivando a interação entre mãe e bebê, facilitando o vínculo afetivo entre ambos.

A experiência vivida pela puérpera gera um momento conflituoso em sua vida, mudanças no seu cotidiano promovendo desequilíbrio emocional em uma situação de estresse. O período de internação acaba separando mãe e filho durante um longo tempo, prejudicando assim os primeiros contatos, que são de extrema importância para a construção e fortalecimento do vínculo afetivo entre os dois. Mediante contextualização surgiram os seguintes questionamentos: Quais os sentimentos das mães diante de um filho internado em uma UTIN? A puérpera se considera inserida no contexto dos cuidados prestados ao RN dentro da UTIN? Será que a assistência da equipe de neonatologia ao RN na UTIN é adequada?

A motivação para realização dessa pesquisa surgiu a partir da experiência em estágio numa UTIN, onde foi possível observar o sofrimento, ansiedade e dúvidas de mães que tinham poucas informações e acesso aos seus filhos. A relevância desse estudo consiste em conhecer as percepções e expectativas dessas mulheres durante o período de internação do seu filho numa UTIN, no sentido de amenizar o impacto gerado pela problemática vivenciada, através da assistência de saúde mais humanizada. 


\title{
Unidade de Terapia Intensiva Neonatal (UTIN)
}

A Unidade de Terapia Intensiva Neonatal, ou UTIN, é um ambiente destinado para o tratamento de recém-nascidos prematuros e de bebês que apresentem algum tipo de problema ao nascer, que são considerados de risco. A UTI neonatal possui os principais recursos humanos e materiais para dar apoio ininterrupto às funções vitais dos recém-nascidos que são encaminhados para a unidade. É composta por uma equipe multidisciplinar e por equipamentos modernos como incubadoras, monitores, respiradores e dispõe de atendimento por 24 horas (BRASIL, 2001).

As UTIN's vêm investindo em novas tecnologias possibilitando a sobrevivência de RN altamente imaturos. $\mathrm{O}$ nascimento de prematuros vem tornando-se freqüentes e apresentam quadros delicados com internações prolongadas. Exigindo que a equipe neonatal esteja preparada para lidar com situações complexas como: prestar cuidado ao RN com quadro clinico instável podendo comprometer seu desenvolvimento no futuro, superação de angustias e expectativas diante de alguns casos, interagir junto a mãe nos cuidados oferecidos ao RN amenizando o estado de tristeza e dor.

Simões (2002) afirma que "o desenvolvimento de Unidades de Terapia Intensiva Neonatal, associado à tecnologia mais avançada, constitui um meio importante no tratamento e sobrevida de neonatos graves". Os avanços tecnológicos são resultados da capacidade de permitir que o homem crie as UTIN's para melhorar o desenvolvimento dos prematuros.

Raad apud Brasil (p.1, 2006), diz que:

\begin{abstract}
“a Unidade de Terapia Intensiva Neonatal é um ambiente que necessita de uma atenção especial, por está marcado por fortes emoções, conflitos e sentimentos, envolvendo desde o ambiente em si até os integrantes: o bebê internado, os pais, os familiares e a equipe de profissionais. Cada um deles apresenta grau de vulnerabilidade, necessidades particulares e específicas que devem ser adequadamente atendidas".
\end{abstract}

Assim, entende-se que estes integrantes devem estar, preferencialmente, em intensa harmonia, para que a situação torne-se menos dolorosa para o bebê e para os pais. Em relação a equipe profissional, os pais devem manter-se confiantes, pois qualquer insegurança pode acarretar um episódio de desconforto tanto para os profissionais da saúde quanto para a família do recém-nascido.

Lago et al., (2007) relata que a Unidade de Terapia é um ambiente repleto de fatores estressores, envolvidos na estabilidade clinica e sobrevida do bebê, dentre eles: luminosidade intensa e constante, ruídos diversos, manipulação excessiva, períodos diminuídos de sono e procedimentos que causam dor e desconforto. Ao cuidar de um RN dentro na UTIN é preciso mais que conhecimento científico e técnicas adequadas, é ter uma visão mais humana, um cuidar sensível. 


\section{O RN prematuro na UTIN}

A OMS (Organização Mundial de Saúde) e a FIGO (Federação Internacional de Ginecologia e Obstetrícia) definem que a prematuridade se da quando há interrupção da gravidez antes de completar 37 semanas. Não significando que o RN deverá ir para UTIN, isso dependera do seu estado clinico.

De acordo com Rabelo et al., (2007), a classificação para o nascimento de um RN prematuro se da através da seguinte divisão:prematuro limítrofe entre 37 e 38 semanas de gestação, em geral sem complicações importantes; prematuro moderado entre 31 e 36 semanas de gestação e prematuro extremo entre 24 e 30 semanas de gestação, sendo que estes apresentam maior instabilidade clinica especialmente os menores de 27 semanas.

Para Donna (1999) não é só a prematuridade que coloca os bebês em risco de complicações neonatais, mas também outros fatores de alto risco. As pesquisas mostram que o maior índice de nascimento de prematuros ocorre na classe socioeconômica baixa devido ao não acompanhamento adequado das gestantes durante os pré-natais, acarretando fatores como pré-eclâmpsia, problemas placentários dentre outros interrompendo assim o desenvolvimento normal da gestação.

Baracho (2007) afirma que "é necessária uma comparação entre o ambiente intra-uterino e a UTIN para avaliar a complexidade dos problemas enfrentados pelo neonato". Ao fazermos tal comparação percebemos que o ambiente intra- uterino é acolhedor, há um controle térmico adequado, poucos estímulos sensoriais que garante as necessidades nutricionais e respiratórias ao RN.

Em relação ao ambiente hospitalar, especificamente a UTIN, é um ambiente completamente divergente do meio intra-uterino. Dessa forma, o RN encontrará dificuldades de adaptação na UTIN, pois este meio, na sua maioria, encontra-se repleto de luzes fortes, ruídos, diferenças de clima e estas variações podem alterar o padrão de conforto do RN.

Tratar um recém-nascido prematuro é um processo complexo que requer uma avaliação rigidamente criteriosa. Na maioria das vezes o bebê mantém-se conectado a aparelhos, daí inicia-se o processo de adaptação tanto do bebê como da mãe, pois esta passa a viver uma experiência totalmente diferente da que imaginava durante a gestação.

\section{RN prematuro: $o$ impacto da prematuridade na relação mãe-bebê}

A gestação é um momento sublime, onde toda a família cria expectativas diante do nascimento do novo ser que está para chegar. Quando o nascimento é prematuro essas expectativas ainda são mantidas, porém, fatores como baixo peso, imaturidade de órgãos ou sistemas tomam a frente e tornam-se motivo de internação em UTIN essas expectativas se fragilizam e fazem com que toda a família, principalmente a mãe, sinta-se mal e impotentes diante desta situação.

Bolwerk apud Lamy \& Gomes (p.20, 2009), diz que: 
"ao estudarem as situações vivenciadas por pais de RN internados na UTI neonatal, constataram que a fragilidade e a insegurança adicionadas aos sentimentos de culpa, por se responsabilizarem pelas necessidades de saúde do filho, ocasionavam neles um grande estress psicológico, principalmente na mãe".

O longo período em que o bebê fica na UTIN, dificulta o processo de vinculação e apego entre mãe e bebê, ocorrendo insegurança em relação à promoção de cuidados ao filho. $\mathrm{O}$ bebê prematuro $\mathrm{e}$ seus familiares têm muitas diferenças iniciais. "Os pais são raramente preparados para sua primeira visão de um bebê magro e mantidos por monitores. A comunicação inicial ocorre primeiramente com a equipe de saúde e não com o seu bebê" (DIAS et al., apud LOPES ,2006).

A equipe de saúde deve apresentar paciência, organização, conhecimento e competência para auxiliar a mãe no processo de cuidado do RN, tentando reduzir expectativas que possam dificultar a adaptação, levando em consideração a qualidade de vida de ambos. A presença da genitora na UTIN é fundamental para amenizar a situação, mas não somente a presença física como também o envolvimento emocional e mental, devendo ela está preparada para as mudanças temporárias que possam ocorrer na sua vida, impostas pela chegada do $\mathrm{RN}$ prematuro.

Além dos cuidados da equipe de saúde, voltados para a recuperação e desenvolvimento do RN, a vivência com a mãe através da estimulação tátil e auditiva, proporcionam a humanização do atendimento neonatal, havendo uma maior rapidez no ganho de peso, como resposta imediata dos estímulos afetivos, sensoriais e motores e facilitando também o vínculo e o apego materno.

\section{Metodologia}

O presente estudo teve como proposta metodológica a pesquisa descritiva com abordagem qualitativa. A pesquisa foi desenvolvida na Unidade de Terapia Intensiva Neonatal do Hospital Maternidade São Lucas da cidade de Juazeiro do Norte-CE, que atende pacientes com procedência de varias cidades da região, além dos oriundos de outros estados. Atualmente conta com 24 leitos de internação, onde 14 para recém-nascidos em observação e prematuros e 10 leitos para alto risco. Assim todos os neonatos que nascem com alguma patologia são encaminhados a UTIN e distribuídos pelos setores de acordo com o nível de complexidade da condição clinica dos mesmos.

Os dados foram coletados com as puérperas presentes nos meses de setembro e outubro de 2014. A população do estudo foi composta por puérperas com recém-nascidos prematuros internados na UTIN, que acompanhavam os mesmos durante o período de internação, onde as mães têm livre acesso a Unidade de Terapia Intensiva Neonatal, estando em tempo integral nos cuidados prestados ao RN. Não interferiu na pesquisa limites de idade, grau escolar ou numero de gestações. 
A amostra adotou critérios de inclusão em que os sujeitos foram limitados as puérperas de recém-nascidos que tinham a classificação de prematuros de acordo com a OMS. Considerada prematura todas as crianças nascidas antes de 37 semanas completas de gestação (BRASIL, 2001). Como exclusão, a amostra foi delimitada através do critério de saturação, que consiste na eliminação de participantes a partir do momento em que as respostas da entrevista tornam-se repetitivas (FIGHERA \& VIERO apud MUCHIELLI, 2005).

Como instrumento de coleta de dados foi utilizado uma entrevista e o método da observação durante a mesma. A entrevista foi realizada através de um roteiro de entrevista semi - estruturado, contendo seis perguntas abertas, foi procedida em um local reservado, e suas identidades foram preservadas através de codinomes que reportaram os seguintes números: Puérpera 1 , Puérpera 2,....., Puérpera 20.

A pesquisa obedeceu aos aspectos éticos contidos na Resolução n ${ }^{\circ}$ 196/96 do Conselho Nacional de Saúde que regulamenta a pesquisa em seres humanos (Ministério da Saúde). Garantido o anonimato das entrevistadas, o sigilo das informações e o direito de interromper a participação em qualquer momento. Foi enviada a instituição o pedido de autorização para a realização da pesquisa junto à cópia do projeto, onde foi autorizado pelo diretor do referido Hospital. Para cada puérpera foi entregue um termo de consentimento livre e esclarecido com a justificativa, os objetivos e os procedimentos utilizados na pesquisa, onde confirmando a sua participação.

\section{Resultados e Discussões}

As entrevistas foram transcritas e analisados os depoimentos, como técnica de análise de conteúdo, tornando a análise temática com as seguintes divisões: pré-analise, discussão dos depoimentos e interpretação dos depoimentos. Na pré-analise ocorreu a seleção das entrevistas que continham respostas importantes para análise. A discussão dos depoimentos foram submetidas a várias leituras, organizando e sistematizando o início e o final de cada resposta diante da pergunta analisada. $\mathrm{Na}$ interpretação dos depoimentos identificamos e nomeamos as perguntas associadas aos objetivos do estudo.

Após qualificar as respostas as mesmas foram definidas e divididas em duas categorias: 1Vivenciando uma difícil experiência de ver seu filho internado na UTIN; 2- Percebendo os sentimentos das puérperas frente ao seu filho internado na UTIN. 


\section{Categoria 1: Vivenciando uma difícil experiência de ver seu filho internado numa UTIN.}

Nesta categoria as entrevistadas relatam os motivos pelo qual o $\mathrm{RN}$ foi internado e suas reações ao saber que iria para UTIN. A mulher quando espera o nascimento de uma criança passa a idealizar esse momento, criando expectativas de um ser saudável sem nenhuma complicação, contudo quando se deparam com as adversidades de um parto prematuro, gera sentimentos de impotência e insegurança que fragilizam muito essas mulheres.

A internação do RN na UTI neonatal causa impacto emocional na puérpera, desencadeando comportamentos de fracasso, medo, angustia e sentimentos de perda relacionada ao nascimento de um bebê real diferente do imaginário, mostrando que ela necessita de apoio da equipe neonatal.

Diante desse contexto constamos a importância da utilização de uma linguagem simples e acessível dos profissionais da UTIN com as mães, disponibilizando informações concretas sobre o estado de saúde do seu filho minimizando as ansiedades geradas pela situação em questão.

Através das puérperas entrevistadas, percebe-se que a maioria sabia o motivo pelo qual seu filho foi internado na UTIN como pode ser observado nas falas abaixo:

\footnotetext{
"Sim. Porque tem problema respiratório e no pulmão” (Puérpera 7).

"Sim. Por causa que ele nasceu prematuro. Ai nasceu com menos de dois quilos, ai tem que pegar peso”" (Puérpera 9).

"Sim. Diz os médicos que ela inalou fezes dentro da barriga antes de nascer e não chorou” (Puérpera 19).

“Não. Assim nasceu fora do tempo e não pesou muito (Puérpera 13).

“Não. Eu acho que foi prematuro e tava precisando de oxigênio (Puérpera 20).
}

Esses relatos mostram que antes de qualquer explicação técnica o profissional deve perceber o quanto essa mãe é capaz de entender, levando em conta suas dúvidas. Mostrando que a equipe pode mudar a situação beneficiando o processo de adaptação das puérperas (BARROS, 2004).

\footnotetext{
"Eu já estava preparada, o médico já tinha me dito" (Puérpera 1).

"Eu fiquei muito desesperada na hora, sem saber o que pensar e o que fazer.
} Porque foi uma situação horrivel por ser meu primeiro filho, fiquei muito aflita" (Puérpera 6).

"Há quase morri... deu um colapso. Não gosto nem de lembrar, fiquei desesperada" (Puérpera 11).

"Eu nem pensei. Eu pensava que ele ia morrer" (Puérpera 14).

"Eu assim... eu reagi assim... eu fiquei triste, porque fiquei indefesa, abalada, sem saber o que fazer, eu não entendia" (Puérpera 15). 
Chamam a atenção os relatos, pois evidencia o impacto da situação vivenciada por essas mulheres, que acabam de se tornarem mães, mas ao invés de terem em seus braços um filho saudável no aconchego do seu lar, vivenciam uma realidade oposta, a qual se deparam com um filho apresentando um estado de saúde delicado, necessitando de cuidados especializados num ambiente estranho como a UTIN. Tendo, portanto essa mulher que se adaptar da melhor forma a essa nova realidade.

\section{Categoria 2: Percebendo os sentimentos e dificuldades das puérperas frente ao seu filho internado na UTIN.}

Nesta categoria percebemos que as puérperas expressam seus sentimentos através de um significado negativo, doloroso e ameaçador da UTIN, permeado de tristeza, angustia desespero e medo da morte. Nota-se também ao mesmo tempo o reconhecimento do valor positivo da UTIN de salvar vidas. Mediante análise observam-se os relatos a seguir:

\footnotetext{
"Bom, no começo fiquei muito angustiada em vê-lo todo intubado na UTI, mas com o tempo estou me acostumando” (Puérpera 4).

"Não me sinto bem. Queria que ele fosse para casa, mais esta sendo bem cuidado e é o que importa” (Puérpera5).

"Sinto uma tristeza e alegria, porque ela vai ganhar peso e vai sair e a tristeza porque me sinto culpada por ela estar aqui” (Puérpera 9).

"Eu fico com o coração partido, eu fico tão fragilizada, no inicio eu não olhava para ele porque eu não agüentava. Achava que ia morrer” (Puérpera 14).

"Eu me sinto agora segura, pois sei que estão cuidando bem. Pois o melhor para ele é ficar ai, ate que de pra ele sair" (Puérpera 15).
}

É importante inferir que um dos principais sentimentos expressados pelas puérperas foi a angustia de não poder pegar seu filho no colo e amamentar. $\mathrm{O}$ fato da mulher produzir o próprio alimento para o $\mathrm{RN}$,envolve vários fatores físicos e emocionais e quando prejudicado acaba influenciando nas expectativas geradas causando um problema para essas mães pelo fato de não conseguirem suprir as necessidades do seu filho de forma natural.

$\mathrm{O}$ fato da criança permanecer internada em uma unidade de terapia intensiva logo após o nascimento pode ser um fator que contribua para a experiência da amamentação se tornar, alem de nova, também difícil. 
"É muito ruim a sensação. O que a gente que é ter o filho da gente, e poder amamentar” (Puérpera 4).

“Terrivel! Porque o maior prazer da mãe é dar o leite do peito e hoje nem pela seringa eu consegui fazer isso" (Puérpera 6).

“Que a gente só se sente mãe quando esta amamentando. Que é bom” (Puérpera 8).

“Me senti muito triste, pois não sabia a sensação de ser mãe. Eu fiquei assim... pensando qual seria o dia que eu vou poder amamentar" (Puérpera 15).

$\mathrm{O}$ ato de não poder amamentar surpreende e frustra as mães passando de um processo instintivo e fácil para um processo doloroso e difícil. Ficando evidente o papel do profissional em incentivar a participação das puérperas nos cuidados com seu filho, pois quanto mais cedo essa mãe for integrada dentro da UTIN, melhor ela conseguira lidar com a internação prolongada.

\section{Conclusão}

Neste estudo ficaram evidenciados, a partir das falas das entrevistadas os seus sentimentos e percepções diante de ter seus filhos prematuros internados em uma UTIN. Chega-se a conclusão que as puérperas ao se depararem com a notícia da hospitalização do RN e posteriormente com a impossibilidade de dar assistência ao mesmo logo após o nascimento, mostram-se desesperadas, nervosas, tristes e com medo da morte diante da nova realidade.

Foi observado que as mães participam dos cuidados ao $\mathrm{RN}$, a equipe da neonatologia as inserem no contexto da UTIN, porém a um período de adaptação que depende do quadro clinico da criança para as puérperas iniciarem a assistência.

Os profissionais de saúde estimulam as mães a participarem dos cuidados com os seus filhos onde contam com um apartamento de apoio dentro do hospital, local que é dedicado para o descanso ajudando no aleitamento materno que nessa fase é através do desmame, proporcionando a elas estarem presentes em tempo integral com seu filho e livre acesso na UTIN.

Ao serem inseridas no contexto dos cuidados prestados pela equipe de saúde, a maioria ressalta que as ações dos profissionais são indispensáveis e contribuem para a integridade física do RN. Tornado-se uma questão positiva, o apoio oferecido em relação a aproximação do vinculo afetivo mãe-bebê dentro da UTIN. Mostrando que esta sendo cada vez mais atuante dentro dos hospitais o ato dos cuidados humanizados.

Acredito que este estudo tenha contribuído para o saber e $\quad m$ saúde a medida que descreve os sentimentos e percepções de puérperas dentro das rotinas de uma unidade de terapia intensiva altamente complexa, podendo promover uma reflexão dos profissionais atuantes nesse 
cenário, fazendo com que percebam mais os sentimentos que as mães emitem durante a sua permanência no acompanhamento do RN na UTIN.

Neste estudo, devemos perceber que caminhamos na direção certa quando voltamos nossos olhares para compreendermos as dificuldades maternas vivenciadas, pois só as mães podem expressar suas percepções diante da problemática, cabendo ao profissional reduzir o impacto gerado e interferir na aproximação do vinculo afetivo o mais rápido possível para o beneficio mãe-filho.

\section{Referências}

BARACHO, E. Fisioterapia aplicada a obstetrícia uroginecologia e aspectos de mastologia. $4^{\circ}$ ed. Rio de Janeiro: Guanabara Koogan, 2007.

BARROS. et al. Vivencias paternas em UTI neonatal. Programa de pós-graduação em Psicologia. Universidade Federal do Espirito Santo, Brasil, 2004.

BOLWERK, G. A. A. A UTI Neonatal: Uma visão materna. Secretaria de Estado de Saúde Hospital Regional da Asa Sul. Residência em Neonatologia, p.20, 2008.

BRASIL. Humaniza SUS: Política Nacional de Humanização: a humanização como eixo norteador das práticas de atenção e gestão em todas as instâncias do SUS. Ministério da saúde, Secretaria Executiva, Núcleo Técnico da Política Nacional de Humanização- Brasília. Ministério da Saúde, 2004.

BRASIL. Ministério da Saúde. Como ajudar as mães a amamentar. 2001.

DIAS, N.M. MALZONE, P. H. P.; SOARES, C.; PIANOWINSKY, G.; TORRES, J. C. \& PIMENTEL, C. A. A UTI Neonatal - A Educação no Ambiente Hospitalar: Proposta de esclarecimento a pais e acompanhantes. Universidade São Francisco, 2006.

DONNA, L. W. Enfermagem pediátrica: Elementos essenciais à intervenção efetiva, 5 ed., editora Guanabara Koogan, 1999.

FIGHERA, Jossiele \& VIERO, E. Venturini. Vivências do paciente com relação ao procedimento cirúrgico: fantasias e sentimentos mais presentes. Rev. SBPH vol. $8 \mathrm{n}^{\circ} .2$. Rio de Janeiro, 2005. Disponível em: $\quad$ http://pepsic.bvs-psi.org.br/scielo.php?script=sci_arttext\&pid=S151608582005000200005\&lng= en\& nrm $=$. Acesso: $27 / 05 / 09$.

LAGO et al. Avaliação e manejo da dor neonatal no contexto da unidade de terapia intensiva neonatal (UTIN). p.10-44, Brasilia, 2007.

MARCONI, M. \& LAKATOS, E. Fundamentos de metodologia científica. $6^{\circ}$ edição. São Paulo, Editora Atlas, 2005.

MINAYO,M.C.S. O Desafio do conhecimento : pesquisa qualitativa em saúde. $9^{\circ}$ edição.São Paulo, Editora Hucitec, 2006. 
MINISTERIO DA SAÚDE (BR). Conselho Nacional de Saúde. Diretrizes e normas regulamentadoras de pesquisas envolvendo seres humanos. Resolução CNS n 196, de 10 de outubro de 1996. Inf Epidemiol SUS, 1996, 5(2 supl 3): 13-41.

RAAD, A.J. et al. A realidade das mães numa unidade de terapia intensiva neonatal. Revista Psic, v.07, nº. 02, p. 1, 2006.

RABELO, M.Z.S. et al. Sentimentos e expectativas das mães na alta hospitalar do recém-nascido prematuro. Acta Paulista de Enfermagem, v.20, nº. 03, p. 333-337, 2006.

SIMÕES, A. Manual de Neonatologia. Editora Guanabara Koogan, 2002

\section{Como citar este artigo (Formato ABNT):}

ALENCAR

S , S.A.; BEZERRA, M.M.M. Percepções das Puérperas frente ao recém-Nascido na UTI Neonatal de um Hospital em juazeiro do Nrte - CE. Id on Line Revista de Psicologia, Julho de 2015, vol.9, n.27. p. 205-215. ISSN 1981-1189.

Recebido: 04/02/2015

Aceito:13/03/2015 